\title{
Adaptation to Partial Resistance to Powdery Mildew in the Hop Cultivar Cascade by Podosphaera macularis
}

David H. Gent, U.S. Department of Agriculture-Agricultural Research Service, Forage Seed and Cereal Research Unit, Corvallis, OR 97331; and Oregon State University, Department of Botany and Plant Pathology, Corvallis, 97331; and Stephen T. Massie, Megan C. Twomey, and Sierra N. Wolfenbarger, Oregon State University, Department of Botany and Plant Pathology, Corvallis, 97331

\begin{abstract}
The hop cultivar Cascade has been grown in the Pacific Northwestern U.S. and elsewhere with minimal input for management of powdery mildew (Podosphaera macularis) for nearly 15 years due to the putatively quantitative resistance in this cultivar. While partial resistance is generally thought to be more durable than qualitative resistance, in 2012, powdery mildew was reported on Cascade in Washington State. Field surveys conducted during 2013 to 2016 indicated increasing prevalence of powdery mildew on Cascade, as well as an increasing number of fungicide applications applied to this cultivar in Washington State. Nearly all isolates of $P$. macularis tested were able to infect Cascade in laboratory inoculations. However, the greatest number of colonies, most conidia produced, and the shortest latent period was only observed with isolates derived originally from Cascade, as compared with other isolates derived from other cultivars. Further, the enhanced aggressiveness of these isolates was only

manifested on Cascade and not six other susceptible cultivars, further indicating a specific adaptation to Cascade by the isolates. There was no evidence of a known major R-gene in Cascade, as seven isolates of $P$. macularis with contrasting virulence all infected Cascade. Among 158 isolates obtained from hop yards planted to Cascade, only two $(1.3 \%)$ were able to infect the cultivar Nugget, which possesses the resistance factor termed R6, indicating that isolates of $P$. macularis virulent on Nugget are largely distinct from those adapted to Cascade. Further, race characterization indicated Cascadeadapted isolates of $P$. macularis were able to overcome $\mathrm{R}$-genes $\mathrm{Rb}, \mathrm{R} 3$, and R5, but not other known R-genes. Therefore, multiple R-genes and other sources of partial resistance are expected to provide resistance to Cascadeadapted strains of the fungus. Given the plasticity of the powdery mildew fungus, breeding strategies for powdery mildew need to consider the potential for adaptation to both qualitative and partial resistance in the host.
\end{abstract}

Hop production in the Pacific Northwestern U.S. (Washington, Oregon, Idaho) has required management of powdery mildew since the introduction of Podosphaera macularis in the mid-1990s (Ocamb et al. 1999). While a combination of methods are utilized to manage the disease over a growing season, host resistance is the most desired due to the reduction of inputs required. Resistance can be obtained in a given cultivar by an assortment of genetic mechanisms, including but not limited to qualitative (major gene) and quantitative (minor gene) resistance. Independent of the nature of resistance, durable resistance is preferred because of the time and resources required to identify and develop resistance in a cultivar. Herein, durable resistance is defined as resistance that remains effective over a long period of time while being broadly deployed in a favorable environment (Johnson 1981). Identification of durable resistance can be challenging and typically is retrospective. In many pathosystems, the most durable resistance is associated with quantitative resistance, combinations of quantitative and qualitative R-genes, or combinations of R-genes (Brun et al. 2010; Clair 2010; Fukuoka et al. 2015; Li et al. 2001; McDonald and Linde 2002; Mundt 1990; Palloix et al. 2009; Quenouille et al. 2013; Tan et al. 2010).

Though generally recognized to be less durable than other forms of resistance, qualitative resistance is often utilized in breeding

Corresponding author: David H. Gent, E-mail: dave.gent@ ars.usda.gov

The use of trade, firm, or corporation names in this publication is for the information and convenience of the reader. Such use does not constitute an official endorsement or approval by the United States Department of Agriculture or the Agricultural Research Service of any product or service to the exclusion of others that may be suitable.

*The $\boldsymbol{e}$-Xtra logo stands for "electronic extra" and indicates that three supplementary tables are available online.

Accepted for publication 26 January 2017.

This article is in the public domain and not copyrightable. It may be freely reprinted with customary crediting of the source. The American Phytopathological Society, 2017. programs due to its ease of selection, especially in juvenile plants where large numbers of individuals can be screened inexpensively. Unlike qualitative resistance, quantitative resistance is normally derived from multiple genes, each with a small, additive contribution to disease resistance, resulting in a continuous distribution of disease phenotypes in a genetically segregating population (Clair 2010; Lander and Botstein 1989; Poland et al. 2009). Quantitative resistance is often reported to be more durable than resistance conditioned on a major R-gene, although pathogen adaptation to quantitative resistance has been reported in several pathosystems (Andrivon et al. 2007; Pariaud et al. 2009; Rouse et al. 1980). Resistance in a given cultivar can be eroded when the percentage of that cultivar increases rapidly in production (Bonman et al. 1992; Wolfe and Schwarzbach 1978). The increase in that particular genotype in the field allows selection of an increasingly aggressive strain of the pathogen for a given cultivar, the so-called "boom and bust" cycle of host resistance (Andrivon et al. 2007; McDonald and Linde 2002; Mundt 1994; Rouxel et al. 2003; Villaréal and Lannou 2000).

In the hop powdery mildew pathosystem, qualitative resistance currently utilizes seven known resistance loci or genes, dubbed $\mathrm{Rb}$, R1, R2, R3, R4, R5, and R6 (Darby 2001; Neve 1991; Seigner et al. 2001; Wolfenbarger et al. 2016a). A differential set of (nonisogenic) hop cultivars associated with these R-genes has been used in multiple studies for race characterization of $P$. macularis (Oberhollenzer and Seigner 2011; Seigner et al. 2001; Wolfenbarger et al. 2016a). A few of these loci have been histologically characterized (Royle 1978; Seigner et al. 2001), and genetic markers associated with R1, R2, and R6 have been identified (Kozjak et al. 2009). Furthermore, susceptibility to powdery mildew varies among cultivars and partial resistance conditioned by quantitative trait loci (QTL) is thought to exist in multiple sources of germplasm (Darby et al. 1989). To date, no studies have reported on the characterization of quantitative resistance to powdery mildew on hop, nor have QTL been reported that are associated with such resistance.

Isolates of $P$. macularis exist that can overcome one or more of the known R-genes in hop, although a race virulent to all R-genes has not been reported (Darby et al. 1989; Wolfenbarger et al. 2016a). Of particular relevance, powdery mildew resistance associated with R6 was broadly deployed in the primary hop production regions of the U.S. 
and provided high levels of resistance to the disease for approximately 15 years. However, beginning in 2011 and 2012, outbreaks of powdery mildew on cultivars possessing R6 have become increasingly frequent and severe. At present, isolates of the fungus virulent to all major R-genes except R1 and R2 have been reported in the primary hop production regions in the Pacific Northwestern U.S. (Wolfenbarger et al. 2016a).

Seemingly coincident with the emergence of R6-virulent strains of P. macularis in the U.S. has been the increasing occurrence of powdery mildew on the cultivar Cascade, both in the Pacific Northwestern U.S. and but also in some isolated fields in other regions (Wolfenbarger et al. 2016b). The cultivar Cascade is an aroma-type cultivar that was bred by the U.S. Department of Agriculture and released in 1972 (Brooks et al. 1972). Cascade is presently (and has been since at least 2007) the most widely consumed cultivar by craft brewers (Cantwell 2015), being used by over 4,000 breweries worldwide. Historically, Cascade was considered susceptible to powdery mildew (Neve 1991; Turechek and Mahaffee 2004), but not highly susceptible, and was not severely affected by powdery mildew in the Pacific Northwestern U.S. (Ocamb et al. 1999) despite being grown on at least 3 to 16\% of the hectares in production since 1996 (https://www.nass.usda. gov/). Quantitative estimates of the levels of powdery mildew typically observed under field conditions are not known to exist in the literature. However, to our knowledge, powdery mildew has not been observed beyond trace levels on Cascade under field conditions in the Pacific Northwest. The mechanisms associated with partial resistance to powdery mildew in Cascade are not known with certainty, although segregation ratios from numerous controlled crosses suggest the phenotype is under polygenic control and the partial resistance appears to be quantitative (Peter Darby, personal communication).

The prevalence and incidence of powdery mildew has increased on Cascade since 2012, suggesting an adaptation by the fungus to this host. However, because Cascade is not known to possess a major R-gene, the relationship of $P$. macularis isolates on Cascade to isolates virulent to cultivars possessing resistance based R6 is uncertain. A better understanding of the susceptibility of Cascades to powdery mildew, characterization of potential pathogen adaptation to its resistance, and the implications of the shift in the pathogen population are needed to plan management strategies in both the near and long-term. Thus, this research sought to: (i) describe the geographic extent and incidence of powdery mildew on Cascade in the Pacific Northwestern U.S.; (ii) identify the race of $P$. macularis found on Cascade; (iii) better characterize the resistance to powdery mildew in Cascade; and (iv) determine if isolates derived from Cascade are indeed specifically Cascade-adapted.

\section{Materials and Methods}

Plant materials. Hop plants were propagated from softwood cuttings and grown in a greenhouse free of powdery mildew at 20 to $25^{\circ} \mathrm{C}$ with a $14-\mathrm{h}$ photoperiod. Plants were grown in Sunshine Mix \#1 (Sun Gro Horticulture, Hubbard, Oregon) for approximately 14 to 21 days and were watered daily, receiving Sunshine Technigro 16-17-17 Plus fertilizer with micronutrients (Sun Gro Horticulture) at each irrigation. Isolates of $P$. macularis were maintained on detached hop leaves using standard methods (Wolfenbarger et al. 2015), and transferred every 2 to 3 weeks.

Surveys for powdery mildew on Cascade. Surveys of commercial hop yards were conducted in Oregon and Washington during 2013 to 2016 to determine the incidence (proportion of plants affected) and prevalence (proportion of fields affected) of powdery mildew on the cultivar Cascade. Due to the size of hop production in Washington, the Washington hop growing areas were divided into three regions; the Lower Valley, Yakima Indian Reservation, and Moxee as designated by Turechek et al. (2001). Oregon was not divided into regions because of the relatively smaller scale of hop production in this state. In both Washington and Oregon, disease assessments were conducted during late June to early July using established sampling methods for powdery mildew on leaves (Gent et al. 2006). In brief, two transects (rows) were selected arbitrarily in each yard and 10 leaves were inspected for the presence of powdery mildew on each of 75 plants per transect. Disease assessments were conducted at a single time point, just prior to bloom, because this is typically the period when the incidence of leaves with powdery mildew is maximal in hop (Wolfenbarger et al. 2016a). Disease assessments during the 2013 season included eight yards in Washington (five in the Yakima Indian Reservation, one in the Lower Valley, and two Moxee) and five yards in Oregon. Disease assessments in 2014 included 15 yards in Washington (nine in the Yakima Indian Reservation, three in the Lower Valley, and three Moxee) and eight in Oregon. In 2015, 14 yards total in Washington (eight in the Yakima Indian Reservation, three in the Lower Valley, and three Moxee) and eight in Oregon were assessed. In 2016, 12 yards were assessed in Washington (six in the Yakima Indian Reservation, three in the Lower Valley, three in Moxee) and nine in Oregon.

To better understand the temporal development of powdery mildew on Cascade, in 2013 and 2014, biweekly assessments of the incidence of powdery mildew were made in a subset of four yards in 2013 and six yards in 2014. Disease assessments began in mid-May and continued until late July to early August, which encompasses the period of most rapid vegetative development in hop and bloom when shoot extension and leaf development largely cease (Thomas 1967). Thereafter, disease incidence typically decreases on leaves in commercial production as extant colonies gradually die and leaves become ontogenically resistant (Turechek et al. 2001), as exemplified in the disease progress curves presented in Probst et al. (2016). The data from the disease evaluations was expressed as disease progress curves to deduce when disease incidence began to decrease consistently.

Pesticide application records were obtained from cooperating growers at the end of each season and examined to determine the number of fungicide applications made specifically for powdery mildew. Mixtures of two powdery mildew fungicides used in a single application were considered one application.

The incidence of plants with powdery mildew during the early summer disease assessments and the number of fungicide applications made by growers were analyzed by production region over all years in a generalized linear mixed model using the GLIMMIX procedure in SAS version 9.4 (SAS Institute, Cary, NC). Production region was a fixed effect and year a random effect in the analysis. A random effect for yard nested within region was attempted but removed in the final model due to a 0 variance estimate for this factor. For incidence data, a binomial distribution of the response variable and logit link function was specified. The negative binomial distribution was specified for the fungicide application data, with a logit link function.

Characterization of powdery mildew resistance in Cascade. To improve our understanding of the resistance found in Cascade, inoculations were conducted with seven clonal isolates of $P$. macularis with known race (Table 1) obtained from E. Seigner, Bayerische Landesanstalt für Landwirtschaft, Bavaria, Germany (partially reported in Seigner et al. 2006 and Wolfenbarger et al. 2016a). Each isolate was inoculated to three detached leaves of Cascade and at least one

Table 1. Development of powdery mildew on cultivar Cascade when inoculated with a differential set of isolates of Podosphaera macularis

\begin{tabular}{llllc}
\hline Isolate & $\begin{array}{c}\text { Other } \\
\text { designations }\end{array}$ & Location & \multicolumn{1}{c}{ Virulence $^{\mathbf{y}}$} & Disease $^{\mathbf{z}}$ \\
\hline HPM-198 & BU10 & Germany & V3, V4, V6, Vb & + \\
HPM-199 & Hū9 & Germany & V3, Vb & + \\
HPM-200 & E8 & England & V1, V3, Vb & + \\
HPM-202 & Hofen 1 & Germany & V3, V4, V6, Vb, & + \\
& & & VWH18 & \\
HPM-203 & 2003/198/021 & France & Vb & + \\
HPM-204 & F10 & England & V1, V2, V3, V5, Vb & + \\
HPM-205 & E10 & Germany & V4, V6 & + \\
\hline
\end{tabular}

${ }^{\mathrm{x}}$ Designation from Seigner et al. (2001).

y Virulence of isolate based on reaction when inoculated to a differential set of cultivars, including Yeoman or Buket (Rb), Zenith (R1), Target (R2), Challenger (R3), Serebrianka (R4), Early Choice (R5), and Nugget (R6) as described in Wolfenbarger et al. (2016a). VWH18 indicates growth on a wild hop with an as yet uncharacterized resistance.

${ }^{\mathrm{z}}$ Disease reaction was considered positive if conidiophores of $P$. macularis were visible with $40 \times$ magnification after 21 days of incubation at $18^{\circ} \mathrm{C}$ 
leaf of the susceptible cultivar Symphony (not known to possess any R-genes) with the aid of a small insect pinning needle and dissecting microscope (Wolfenbarger et al. 2016a). Inoculations were repeated at a later time to confirm the initial results. In addition to the isolates with known virulence, 69 other $P$. macularis isolates originating from various cultivars and states were inoculated to Cascade (Supplementary Table S1). The purpose of these inoculations was to determine if Cascade displays an isolate-specific response that confers complete resistance to powdery mildew. Of the isolates used, 18 were obtained from yards planted to Cascade and the others were derived from other cultivars commonly planted in the region.

Furthermore, a total of 158 P. macularis isolates collected from Cascade in Washington, Oregon, and Colorado also were inoculated to the cultivar Nugget, which possess the resistance gene R6 (Wolfenbarger et al. 2016a), to determine the frequency of R6virulence among isolates found on Cascade (Supplementary Table $\mathrm{S} 2$ ). Of these 158 isolates, 14 also were inoculated to Cascade. Reactions were deemed compatible if sporulation was present after 3 weeks of incubation at $18^{\circ} \mathrm{C}$.

Race characterization of Podosphaera macularis isolates. A total of 29 clonal isolates originating from Cascade or with confirmed Cascade-adaptation (Supplementary Table S3), as described in Wolfenbarger et al. (2016b) and below, were obtained by inoculation of a single conidial chain of the fungus onto detached leaves of cultivar Symphony as described in Wolfenbarger et al. (2016a). The majority (27 of 29) of these isolates were obtained from Washington, owing to the limited known occurrence of the disease on Cascade in other states. The other two isolates were collected in 2016 from Oregon and North Carolina. All isolates expect one were originally obtained from Cascade. The isolate from North Carolina was obtained from the cultivar Cashmere, and was previously identified as being Cascade-adapted based on its differential aggressiveness on this cultivar as compared with other isolates (described below and in Wolfenbarger et al. 2016b). Isolates were maintained through successive transfers of conidia on Symphony, with routine transfers to Cascade to ensure selection for Cascade aggressiveness.

To determine pathogen race, isolates were inoculated to three detached leaves from each of seven different plants in a differential set of cultivars. The differential set of cultivars used included Yeoman or Buket (Rb), Zenith (R1), Target (R2), Challenger (R3), Serebrianka (R4), Early Choice (R5), and Nugget (R6), as described previously (Wolfenbarger et al. 2016a). Inoculations were conducted as previously described. Leaves were incubated for 21 days at $18^{\circ} \mathrm{C}$ with a 14-h photoperiod provided by provided by fluorescent lights (32 Watt, Philips F32T8/TL850 800 series Alto Fluorescent). A reaction was considered positive if conidiophores of the fungus were visible with $40 \times$ magnification.

Cascade-adaptation in $\boldsymbol{P}$. macularis. As noted previously, Cascade is only partially resistant to powdery mildew. Under field conditions in the Pacific Northwestern U.S., development of powdery mildew on Cascade is rare and historically the cultivar has not been severely affected by the disease. In contrast, under greenhouse conditions, some level of the disease can develop following inoculation and incubation under disease-favorable conditions. Determination of Cascade-adaptation by $P$. macularis in a given isolate requires one to distinguish it from other isolates based on growth characteristics on this cultivar. In this study, we adopted an operational definition of Cascade-adaptation based on one of two factors. Firstly, if an isolate was obtained from a hop yard planted to Cascade with severe disease (e.g., numerous diseased plants and progressive increase of disease over time) and readily infected Cascade under controlled conditions, the isolate was deemed to be putatively Cascade-adapted. For isolates originating from another cultivar, we followed the example of Wolfenbarger et al. (2016b) and Cascade-adaptation was delineated based on a quantitative difference in the number of colonies produced on Cascade as compared with an isolate that was not aggressive on Cascade. An isolate that was originally obtained from Cascade but not assayed for aggressiveness on Cascade is termed "Cascade-derived" herein to disambiguate from isolates where Cascade adaptation was confirmed based on growth as compared with a wild type isolate.
Based on these criteria, a controlled environment experiment was designed to confirm that isolates of $P$. macularis originating from Cascade were indeed uniquely adapted to grow on this cultivar. Nine leaves of Cascade were inoculated with one of three sources of isolates of $P$. macularis. These isolates were: three isolates obtained from heavily diseased Cascade plants in Washington in 2014 (isolates HPM-693, 694, and 697). Three isolates with race Vb, V3, V5 (isolates HPM-663, 668, and 669 were obtained from cultivars Magnum [Oregon in 2014]), an unnamed breeding line [Oregon in 2014], and Tomahawk [Washington in 2014], respectively). Three other isolates (HPM-662, 666, and 672 with race $\mathrm{Vb}, \mathrm{V} 3, \mathrm{~V} 4, \mathrm{~V} 5$, V6 were obtained from Super Galena [Oregon in 2014], Apollo [Washington in 2014], and Bravo [Washington in 2014]). Inoculations were conducted by applying a suspension of 20,000 conidia/ml (in distilled water) of each isolate to leaves with an airbrush sprayer (Preval, Item \# 0226, Coal City, IL) as described by Wolfenbarger et al. (2016a). Each source of inoculum was also applied to two leaves of Symphony as a check to ensure infectivity. Negative controls consisted of two noninoculated leaves of Cascade included for each inoculum source. Leaves were incubated at $18^{\circ} \mathrm{C}$ with a $14 \mathrm{~h}$ photoperiod.

To determine pathogenic fitness among the nine isolates, measurements of latent period, infection severity, and conidia production were made using methods described previously (Wolfenbarger et al. 2016a). Latent period was assessed by nondestructively inspecting each leaf daily with the aid of a stereomicroscope (up to $40 \times$ magnification) for the presence of conidiophores of $P$. macularis. The date when at least $50 \%$ of the leaves (i.e., 5 of the 9 leaves) bore fungal sporulation was considered the latent period. After 10 to 11 days of incubation, approximately two latent periods on a susceptible cultivar at $18^{\circ} \mathrm{C}$ (Turechek et al. 2001), the number of colonies was counted on each leaf. The mean number of conidia produced per leaf was quantified by rinsing conidia from the leaves with a fine spray of atomized water droplets dispensed from an airbrush sprayer, collecting the conidia together from all nine leaves, and enumerating the conidia in multiple aliquots of $8.5 \mu \mathrm{l}$ with the aid of a hemocytometer at 100x magnification.

The experiment was conducted four times, with blocking in time, in a randomized complete block design. Data were firstly analyzed as a generalized linear mixed model in SAS with fixed factors for isolates and replication a random factor. Differences in pathogenic fitness were not detected between isolates obtained from Cascade, so the analysis was repeated based on inoculum source (termed Cascade, non-V6, and V6) with each isolate considered a subsample. Inoculum source was a fixed factor and replication was a random factor. A normal distribution of the response variables was specified after log-transformation to stabilize variance for the number of colonies and conidia produced.

Aggressiveness of Cascade-adapted strains on other cultivars. Cultivars Cascade, Cashmere, Centennial, Chinook, Columbus, Willamette, and Fuggle were inoculated with Cascade-adapted and nonadapted isolates in growth chamber experiments to determine if Cascade-adapted isolates had enhanced aggressiveness on other cultivars. Plants of each cultivar were obtained either from the National Clean Plant Network for Hops or from the National Clonal Germplasm Repository in Corvallis, Oregon, and subsequently propagated as described previously.

For each cultivar, 18 leaves were detached and placed in a double Petri-dish system described previously (Wolfenbarger et al. 2015, 2016a). The leaves were inoculated with an equal mixture of three clonal isolates of P. macularis obtained from Washington in 2014 with confirmed Cascade-adaptation (isolates HPM-693, 694, and 697; described above and below) or three clonal isolates of $P$. macularis from Oregon and Washington obtained from other cultivars and which lacked Cascade- and R6-virulence (isolates HPM-663, 668, and 669). Isolate HPM-663 was obtained from Magnum (Oregon in 2014), HPM-668 was obtained from an unnamed breeding line (Oregon in 2014), and HPM-669 was obtained from Tomahawk (Washington in 2014). The isolates were maintained individually and conidia were collected from each separately using a Preval airbrush sprayer as described previously. The titer of each conidial suspension 
was adjusted to 20,000 conidia/ml, and then mixed by inoculum source to create a composite inoculum with three isolates at equal titers. Inoculations were conducted as described previously by applying a suspension of 20,000 conidia/ml of each composite inoculum source to leaves with a Preval airbrush sprayer. Three additional leaves of each cultivar were left uninoculated as negative controls and three leaves of Symphony were inoculated as positive controls. The leaves were incubated and assessed as described previously.

The experiment was conducted three times, with blocking in time, in a randomized complete block design. There was a factorial structure to the experiment, with factors of cultivar (seven cultivars) and inoculum source (two levels; Cascaded-adapted and nonadapted). Data were analyzed as a generalized linear mixed model in SAS with fixed factors for cultivar, inoculum source, and the interaction of these factors. Replication was a random factor. A normal distribution of the response variables was specified after log-transformation of the number of colonies and conidia produced.

\section{Results}

Surveys for powdery mildew on Cascade. Field surveys in Washington detected powdery mildew at some level in 6 of 8 Cascade yards surveyed $(75 \%)$ in 2013,14 of 15 yards $(93.3 \%)$ in 2014,11 of 14 yards in 2015 (78.5\%), and 10 of 12 yards $(83.3 \%)$ in 2016. The incidence of plants with powdery mildew varied widely among yards where the disease was found, ranging from 0.7 to $100 \%$ of plants (Table 2). In Oregon, powdery mildew was observed only at trace levels ( $\leq 0.5 \%$ of plants) on Cascade during 2013 to 2015. In 2016 , in contrast, powdery mildew was found in three yards. Disease levels were inconsequential in two instances (single affected leaves on 1.3 and $3.3 \%$ of plants), but substantial in one case $(36.7 \%$ of plants).

Among the 10 yards in Washington where disease assessments were conducted over time, the incidence of hop leaves with powdery mildew varied from not detectable to a maximum of $50 \%$ of leaves (Fig. 1). In 9 of the 10 yards, the incidence of affected plants did not increase after 2 July (day of year 183).

In Washington, fungicide applications made on Cascade increased from less than one (0.8) application per year in 2013 to 3.2 to 4.9 per year thereafter (Table 3). In Oregon, mean fungicide applications did not vary significantly during 2013 to 2016 , with the mean number of applications varying from 1.1 to 3.0 per year. There was evidence for a trend $(P=0.076)$ for regional differences in the number of fungicide applications made (Table 2), with growers in the Lower Valley region making at least three more applications as growers in other regions.

Characterization of powdery mildew resistance in Cascade. Of the 69 isolates inoculated to Cascade, 66 infected and produced sporulating colonies within 21 days. The three isolates that did not cause disease were R6-virulent. All isolates with previously characterized race were able to infect Cascade and produce sporulating colonies (Table 1), indicating the absence of a major R-gene in Cascade that prevented growth of certain races of the fungus.

Race characterization of Podosphaera macularis isolates. All isolates derived from Cascade or with confirmed Cascade-adaptation (as described below) were able to infect cultivars possessing Rb, R3, and R5. Only 2 of 158 isolates (1.3\%) obtained from or with confirmed adaptation to Cascade were able to infect Nugget, indicating the majority of these isolates lack R6-virulence.

Cascade adaptation in $\boldsymbol{P}$. macularis. Differences were observed in the fitness of isolates of $P$. macularis when inoculated to Cascade. The latent period of Cascade-derived isolates was 0.3 days shorter $(P=0.024)$ on Cascade plants as compared with the latent period of isolates derived from other cultivars (Fig. 2). Cascade-derived isolates also produced two $\log$ units more conidia $(P<0.0001)$ and a larger number of colonies $(P<0.0001)$ compared with other isolates. Isolates possessing R6-virulence were least fit on Cascade. Therefore, differential aggressiveness was delineated with the Cascadederived isolates, demonstrating Cascade-adaptation.
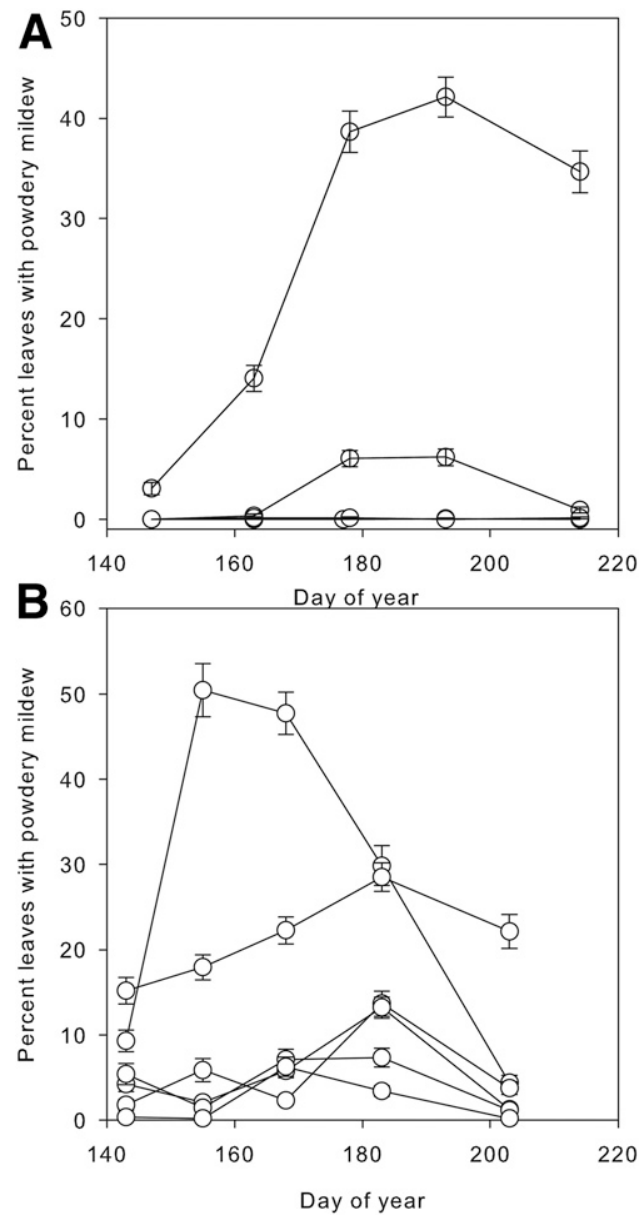

Fig. 1. Disease progress curves for development of powdery mildew (caused by Podosphaera macularis) in commercial hop yards planted to cultivar Cascade in Washington State. Data are incidence of leaves with powdery mildew in each of four yards surveyed in 2013 (A) and six yards in 2014 (B). Error bars indicate standard errors.

Table 2. Incidence of hop plants with powdery mildew (caused by Podosphaera macularis) and number of fungicide applications made to manage the disease by growers in yards planted to cultivar Cascade

\begin{tabular}{|c|c|c|c|}
\hline Production region $y$ & Number of yards & Percent diseased plants (range) ${ }^{\mathrm{Z}}$ & Mean fungicide applications (range) ${ }^{\mathrm{z}}$ \\
\hline Lower Valley & 10 & $1.6 \mathrm{ab}(0-6.7)$ & 6.8 a $(0-11)$ \\
\hline Moxee & 11 & $12.4 \mathrm{ab}(0-68.0)$ & $3.8 \mathrm{ab}(0-8)$ \\
\hline Yakima Indian Reservation & 28 & $47.3 \mathrm{a}(0-100)$ & $2.8 \mathrm{~b}(0-6)$ \\
\hline Oregon & 30 & $1.5 \mathrm{~b}(0-37.3)$ & $2.3 \mathrm{~b}(0-8)$ \\
\hline$P$-value & - & 0.012 & 0.076 \\
\hline
\end{tabular}

y Production regions refer to three hop production regions in Washington State (Lower Valley, Moxee, and Yakima Indian Reservation) and Oregon.

${ }^{\mathrm{z}}$ Disease incidence was assessed in late June to early July during 2013 to 2016. The number of yards assessed reflects the total number of yards over these four years. Data were analyzed in a generalized linear mixed model assuming a binomial distribution for disease incidence and negative binomial distribution for the number of powdery mildew fungicide applications. Values presented above are least square means obtained using an inverse link function for ease of interpretation. Means followed by the same letter are not statistically different at the significance level indicated by the $P$-values. 
Aggressiveness of Cascade-adapted strains on other cultivars. Cultivar and inoculum source interacted to influence disease reaction (interaction term $P \geq 0.015$ for all response variables). Both Cascade-adapted and nonadapted isolates caused powdery mildew on all cultivars evaluated (Fig. 3). However, Cascade-adapted isolates were more aggressive than nonadapted isolates only when inoculated to Cascade based on latent period $(P=0.015)$, number of colonies produced $(P=0.001)$, and the number of conidia produced $(P=0.001)$. On cultivars Centennial and Willamette, the latent period was slightly ( 0.38 and 0.30 days, respectively) yet significantly longer with Cascade-adapted isolates versus nonadapted isolates.

\section{Discussion}

This research establishes that isolates of $P$. macularis with specific adaptation to Cascade are present in the Pacific Northwestern U.S., and elsewhere, and are associated with increasingly frequent outbreaks of powdery mildew on this cultivar. Further, fungicide applications made for powdery mildew on this cultivar have increased commensurately with the increasing occurrence and incidence of the disease in Washington. Regional differences in the incidence of powdery mildew in Cascade yards were observed over the 4 years of this study, with the Yakima Indian Reservation having the highest levels of disease. This is similar to what was observed when R6virulent races of $P$. macularis were first emerging in Washington (Wolfenbarger et al. 2016a) and to powdery mildew levels observed by Turechek et al. (2001) in hop yards lacking R6-resistance. The similarity of these findings probably reflect several differing factors in these regions, such as early season inoculum density, climatic factors, and management practices of the growers in each region.

The adaptation by the fungus appears to be a relatively rare instance of adaptation to partial, quantitative resistance. Two lines of evidence support this contention. Previous reports of powdery mildew susceptibility in Cascade indicate that this cultivar was moderately susceptible, confirming that powdery mildew has been present on this cultivar in the past but at relatively low levels (Neve 1991; Turechek and Mahaffee 2004). In the present study, nearly all isolates of $P$. macularis inoculated to Cascade under laboratory conditions were able to sporulate, including isolates with no known virulence to the R-genes described in hop. Additionally, there were quantitative differences in measures of pathogenic fitness on Cascade among isolates, but these differences were only manifested on Cascade and not on other susceptible cultivars. Whereas Cascade-adapted isolates successfully infected other susceptible cultivars, these isolates were no more fit or aggressive, and possibly less fit, on these cultivars than other isolates of the fungus commonly found in the population. The adaptation of the fungus for increased aggressiveness thus appears to be specific to Cascade and not associated with a known $\mathrm{R}$ gene.

The concomitant emergence of R6-virulent and Cascade-adapted strains of $P$. macularis are due to distinct strains of the pathogen. R6-virulent isolates were found infrequently on Cascade plants in hop yards, poorly infected Cascade under controlled conditions, and belong to a measurably different race. A previous characterization of R6-virulent isolates of P. macularis in the Pacific Northwestern
U.S. found that all were race Vb, V3, V4, V5, V6 whereas all other isolates assayed were Vb, V3, V5 (Wolfenbarger et al. 2016a). In the present study, all Cascade-adapted isolates assayed also were race $\mathrm{Vb}, \mathrm{V} 3, \mathrm{~V} 5$. Isolates of $P$. macularis with R6-virulence can be recovered from cultivars without R6, at frequencies approaching 50\%
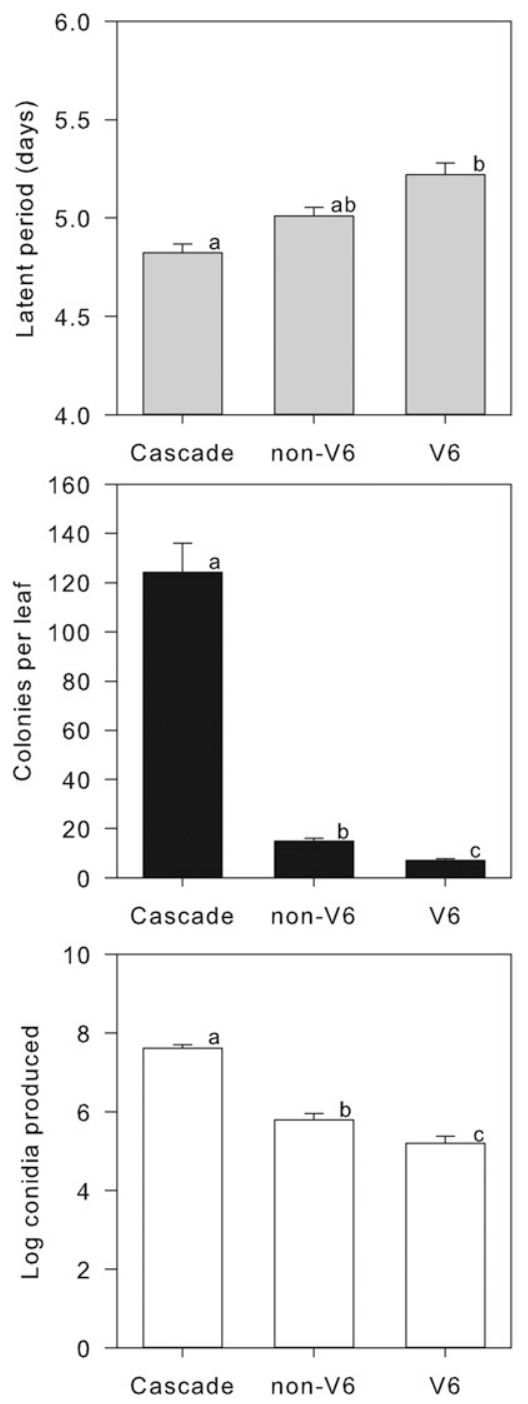

Fig. 2. Adaptation of various isolates of Podosphaera macularis to the hop cultivar Cascade when derived from cultivar Cascade, cultivars lacking R6 (non-V6 isolates), or cultivars possessing R6 (V6 isolates). Three isolates of each phenotype of the fungus were grown individually, adjusted to 20,000 conidia/ml, and then inoculated individually onto nine leaves each. Means followed by the same letter are significantly different based on a mixed model analysis with an F-protected least significant difference test $(\alpha=0.05)$. Error bars indicate standard errors.

Table 3. Yearly variation in the incidence of hop plants of cultivar Cascade with powdery mildew (caused by Podosphaera macularis) and the number of fungicide applications made by growers to manage the disease

\begin{tabular}{|c|c|c|c|c|c|c|}
\hline \multirow[b]{2}{*}{ Year $^{y}$} & \multicolumn{3}{|c|}{ Oregon } & \multicolumn{3}{|c|}{ Washington } \\
\hline & $\begin{array}{c}\text { Number of } \\
\text { yards }\end{array}$ & $\begin{array}{c}\text { Percent diseased } \\
\text { plants (range) }{ }^{\mathrm{z}}\end{array}$ & $\begin{array}{c}\text { Fungicide } \\
\text { applications (range) }\end{array}$ & $\begin{array}{c}\text { Number of } \\
\text { yards }\end{array}$ & $\begin{array}{l}\text { Percent diseased } \\
\text { plants (range) }{ }^{\mathrm{z}}\end{array}$ & $\begin{array}{c}\text { Fungicide } \\
\text { applications (range) }\end{array}$ \\
\hline 2013 & 5 & $0.50 \mathrm{a}(0-2.5)$ & $1.1 \mathrm{a}(0-3)$ & 8 & 39.9 a $(0-99.3)$ & 0.8 c (0-4) \\
\hline 2014 & 8 & 0.08 a $(0-0.7)$ & $3.0 \mathrm{a}(0-8)$ & 15 & 44.1 a $(0-100)$ & $3.2 \mathrm{~b}(0-6)$ \\
\hline 2015 & 8 & 0.19 a $(0-5.0)$ & $2.3 \mathrm{a}(0-5)$ & 14 & 10.1 a $(0-80.7)$ & 4.9 a $(0-11)$ \\
\hline 2016 & 9 & 44.7 a $(0-5.0)$ & $2.2 \mathrm{a}(0-5)$ & 12 & 28.2 a $(0-78.0)$ & $3.8 \mathrm{ab}(0-7)$ \\
\hline$P$-value & - & 0.948 & 0.229 & - & 0.300 & 0.002 \\
\hline
\end{tabular}

y Incidence of plants with powdery mildew was assessed in late June to early July of each year.

${ }^{z}$ Data were analyzed in a generalized linear mixed model assuming a binomial distribution for disease incidence. Values presented above are least square means obtained using an inverse link function for ease of interpretation. Means followed by the same letter are not statistically different at the significance level indicated by the $P$-values. 
depending on the level of disease on cultivar possessing R6 in the region (Wolfenbarger et al. 2016a). Therefore, the infrequent recovery of isolates with R6-virulence from Cascade cannot be explained away as simply an artifact of sampling bias. Collectively, these data provide compelling evidence that R6-virulence and Cascade-adaptation have been selected independently within the population. Race characterization also indicates that breeding programs desiring R-gene-based resistance should focus on R1 and R2, and ideally a combination of the two, which are predicted to provide resistance to most extant strains of the pathogen presently in the region (e.g., R6-virulent, Cascade-adapted, and otherwise).

We postulate that Cascade-adapted isolates of $P$. macularis have been selected from an existing isolate within the population in the $\mathrm{Pa}$ cific Northwestern U.S. This hypothesis is supported by the findings that: Cascade adapted isolates have the same race as the most commonly recovered isolates of $P$. macularis found in the Pacific Northwest (Vb, V3, V5) before 2012; all are mating type MAT1-1 (Wolfenbarger et al. 2015, 2016b), the only mating type found presently in the Pacific Northwestern U.S.; and the emergence of the Cascade-adapted strains corresponded with increased planting of this cultivar. During 2005 to 2016, the percentage of the hop industry planted to Cascade in Washington increased from 5.5 to $13.8 \%$ of the total area (https://www.nass.usda.gov/). Increased planting of Cascade allows for increased exposure of the pathogen to this cultivar, but also likelihood of spread to other susceptible cultivars and survival via bud perennation (Gent et al. 2008).

Consideration of durability of resistance is important in a large, perennial host attacked by a highly fecund pathogen such as a powdery mildew fungus. This is especially important with hops as nearly all of the crop is used in brewing (Hysert 2009) and market factors and customer demands dictate which cultivars are produced. Brewers that have developed products using the cultivar Cascade cannot easily substitute another cultivar that is disease resistant because it is difficult to replicate precisely the brewing characteristics of a given cultivar. Historically, replacement of a hop cultivar utilized for adding flavor or aroma in brewing is a very slow process and done only out of necessity when an existing cultivar is unavailable or its production is threatened (Neve 1991). Replacement of Cascade may be particularly slow because it is presently the most widely produced cultivar in the U.S. and highly important to certain styles of beer (Cantwell 2015). In the immediate and near future, powdery mildew must then be managed where Cascade-adapted isolates of $P$. macularis occur. This will include an increasing number of fungicide applications, increased production expenses, and potentially greater yearto-year variance in yield and crop quality.

Based on the number of fungicide applications made by growers and the incidence of disease observed in the surveys, however, Cascade does not appear to be as susceptible to powdery mildew as some cultivars produced in the region. Wolfenbarger et al. (2016a) reported on similar surveys during the same period on cultivars possessing the resistance factor R6. Estimation of the incidence of plants with powdery mildew in the Washington data from Wolfenbarger et al. (2016a) shows that disease levels on Cascade were similar to the mean disease levels observed on the cultivar Millennium. On highly susceptible cultivars, seven or more fungicide applications are sometimes made to manage powdery mildew in Washington (Sherman and Gent 2014). Comparison of the mean number of fungicide applications made to Cascade in the present study were greater than cultivars Millennium and Nugget, but less than cultivars Apollo and Bravo, as reported by Wolfenbarger et al. (2016a).

It is also notable that disease levels on Cascade appear to diminish more rapidly in early summer (Fig. 1) than on other, susceptible cultivars (e.g., Figure 4 of Turechek et al. 2001). Mahaffee et al. (2003a) stated that powdery mildew development is reduced greatly during summer, when ambient temperatures routinely exceed $30^{\circ} \mathrm{C}$ for the majority of the day in central Washington. Extended periods of supraconducive temperature reduce the infection efficiency and sporulation of P. macularis (Mahaffee et al. 2003b; Peetz et al. 2009), but also moderate leaf susceptibility to the disease (Mahaffee et al. 2003b).
In the present study, Cascade appeared to be relatively susceptible to powdery mildew during the characteristically mild spring weather in central Washington (Fig. 1). However, the rapid decline in disease levels by early summer may suggest that supraconducive temperature attenuates powdery mildew disproportionately more in Cascade as
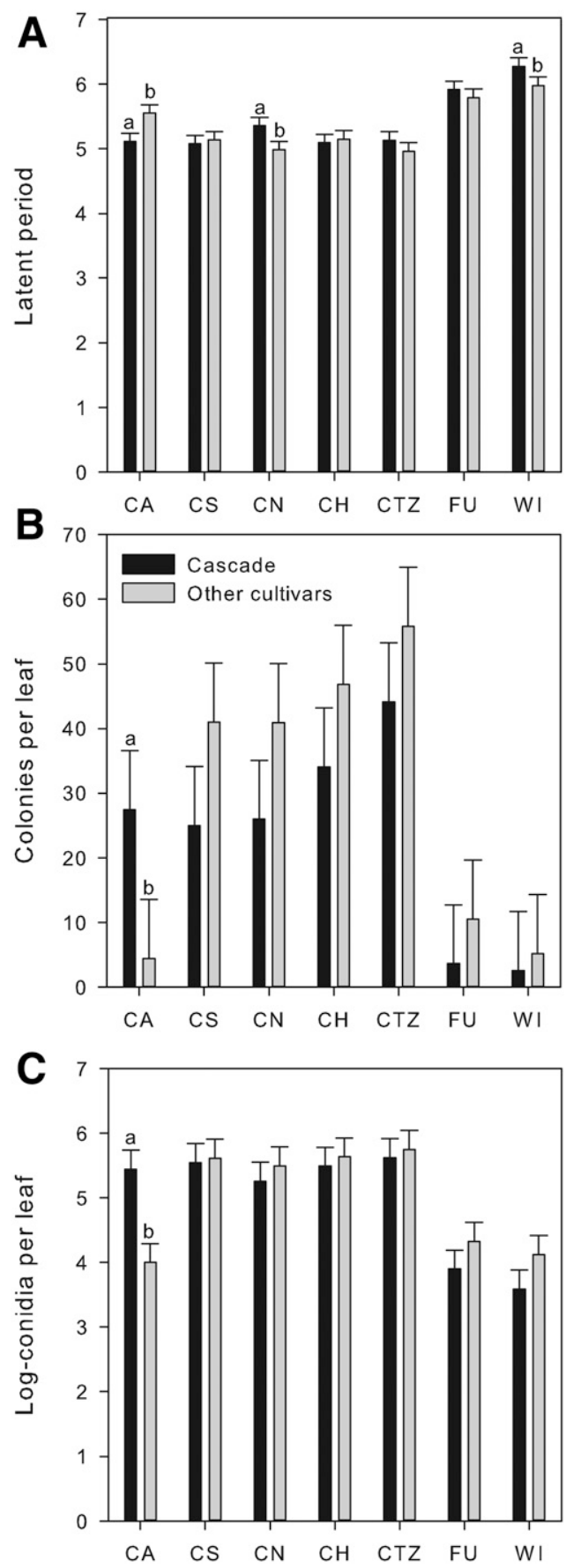

Fig. 3. Pathogenic fitness of Cascade-adapted and non-Cascade-adapted isolates of Podosphaera macularis when inoculated on cultivar Cascade and other hop cultivars susceptible to powdery mildew. Three isolates of each phenotype were grown individually, adjusted to 20,000 conidia/ml, and then mixed to develop a single composite inoculum. On a given cultivar, letters indicate significant differences of the Cascade-derived isolates versus isolates derived from other cultivars based on a simple effect comparison (by cultivar) in a mixed model analysis with an F-protected least significant difference test $(\alpha=0.05)$. There was an inoculum source $\times$ cultivar interaction for latent period $(P=0.015)$, colonies per leaf $(P=0.054)$, and conidia produced $(P=0.001)$. Nontransformed means are presented, although analyses were based on log-transformed data for colonies per leaf and conidia production. Cultivar abbreviations are: $\mathrm{CA}=$ Cascade, $\mathrm{CS}=$ Cashmere, $\mathrm{CN}=$ Centennial, $\mathrm{CH}=$ Chinook, $\mathrm{CTZ}=$ Columbus/Tomahawk/Zeus, $\mathrm{FU}=$ Fuggle, $\mathrm{WI}=$ Willamette. Error bars indicate standard errors estimated from the mixed model analysis. 
compared with certain other susceptible cultivars. Growth chamber studies are in progress to test this hypothesis.

The lack of durability of the partial resistance in Cascade may point to the extreme plasticity of $P$. macularis to adapt to the most prevalent host genotype in the landscape, or alternatively only a moderate (weak) form of resistance in this cultivar. The plasticity of the fungus is especially alarming given that the population in the western U.S. appears to reproduce only asexually (Wolfenbarger et al. 2015). It seems likely that the resistance in Cascade may have been slowly eroding over time but has only recently became apparent because of severe outbreaks of the disease on this cultivar driven by the increase in area planted. A combination of multiple qualitative resistance genes and loci conferring quantitative resistance is thought to give longer lasting resistance (Boyd et al. 2013; Laloi et al. 2016; Liu et al. 2004; Liuv et al. 2009; Mundt 1990, 2014; Quenouille et al. 2014). As demonstrated in the present study and Wolfenbarger et al. (2016a), only R1 and R2 appear to remain effective against most isolates of $P$. macularis in the population in the Pacific Northwestern U.S. In this region, combining these $\mathrm{R}$ genes with quantitative resistance will be important in future breeding efforts to maximize their durability. However, screening for both types of resistance is resource intensive and may be impractical to implement without suitable genetic markers. Validated markers associated with QTL for powdery mildew are not available in hop. Without improved genetic resources and a better understanding of the resistance available in germplasm, selecting for durable resistance will be difficult.

As a final caution, given the movement of planting material throughout the Pacific Northwestern U.S. and outside of the region, it seems likely that Cascade-adapted strains of $P$. macularis will eventually spread elsewhere. The recent confirmation of powdery mildew on Cascade in North Carolina in 2015 (Wolfenbarger et al. 2016b) and Colorado in 2016 (reported herein), with race and/or mating type identical to the isolates only mating type found in the Pacific Northwestern U.S., suggests a possible dissemination of these strains on planting material. Continued monitoring of Cascade hop yards is advisable in areas receiving or distributing planting material from the Pacific Northwestern U.S.

\section{Acknowledgments}

Financial support was provided by USDA-ARS CRIS 2072-21000-046-00, Hop Research Council, Washington State Commission on Pesticide Registrations, and Western IPM Center (grant agreement number Grant Agreement SA7762). We thank Walt Mahaffee and two anonymous reviewers for their reviews and insightful comments that greatly improved this paper.

\section{Literature Cited}

Andrivon, D., Pilet, F., Montarry, J., Hafidi, M., Corbière, R., Achbani, E. H., Pellé, R., and Ellissèche, D. 2007. Adaptation of Phytophthora infestans to partial resistance in potato: evidence from French and Moroccan populations. Phytopathology 97:338-343.

Bonman, J. M., Khush, G. S., and Nelson, R. J. 1992. Breeding rice for resistance to pests. Annu. Rev. Phytopathol. 30:507-528.

Boyd, L. A., Ridout, C., O'Sullivan, D. M., Leach, J. E., and Leung, H. 2013. Plant-pathogen interactions: disease resistance in modern agriculture. Trends Genet. 29:233-240.

Brooks, S. N., Horner, C. E., Likens, S. T., and Zimmermann, C. E. 1972. Registration of Cascade hop (Reg. No. 1). Crop Sci. 12:394.

Brun, H., Chèvre, A. M., Fitt, B. D., Powers, S., Besnard, A. L., Ermel, M., Huteau, V., Marquer, B., Eber, F., Renard, M., and Andrivon, D. 2010. Quantitative resistance increases the durability of qualitative resistance to Leptosphaeria maculans in Brassica napus. New Phytol. 185:285-299.

Cantwell, D. 2015. Outlook good: 2015 BA hop usage survey. The New Brewer 32:91-97.

Darby, P. 2001. Single gene traits in hop breeding. Pages 76-80 in: Proc. Scientific Commission of the International Hop Growers Convention, E. Seigner, ed., Aug 6 to 10, Canterbury, U.K

Darby, P., Mansfield, J. W., and Godwin, J. R. 1989. The assessment of partial resistance to powdery mildew disease in hops. Plant Pathol. 38:219-225.

Fukuoka, S., Saka, N., Mizukami, Y., Koga, H., Yamanouchi, U., Yoshioka, Y., Hayashi, N., Ebana, K., Mizobuchi, R., and Yano, M. 2015. Gene pyramiding enhances durable blast disease resistance in rice. Sci. Rep. 5:7773.

Gent, D. H., Mahaffee, W. F., and Turechek, W. W. 2006. Spatial heterogeneity of the incidence of powdery mildew on hop cones. Plant Dis. 90:1433-1440.

Gent, D. H., Nelson, M. E., George, A. E., Grove, G. G., Mahaffee, W. F., Ocamb, C. M., Barbour, J. D., Peetz, A., and Turechek, W. W. 2008. A decade of hop powdery mildew in the pacific northwest. Online. Plant Health Progress doi: 10.1094/PHP-2008-0314-01-RV.

Hysert, D. 2009. Cone use and chemistry. Pages 8-11 in: Compendium of Hop Diseases and Pests. W. F. Mahaffee, S. J. Pethybridge, and D. H. Gent, eds. APS Press, St. Paul, MN.

Johnson, R. 1981. Durable resistance: definition of, genetic control, and attainment in plant breeding. Phytopathology 71:567-568.

Kozjak, P., Jakše, J., and Javornik, B. 2009. Isolation and sequence analysis of NBS-LRR disease resistance gene analogues from hop Humulus lupulus L. Plant Sci. 176:775-782

Laloi, G., Vergne, E., Durel, C. E., Le Cam, B., and Caffier, V. 2016. Efficiency of pyramiding of three quantitative resistance loci to apple scab. Plant Pathol. (online): http://onlinelibrary.wiley.com/doi/10.1111/ppa.12581/abstract doi: $10.1111 /$ ppa. 12581

Lander, E. S., and Botstein, D. 1989. Mapping mendelian factors underlying quantitative traits using RFLP linkage maps. Genetics 121:185-199.

Li, Z. K., Sanchez, A., Angeles, E., Singh, S., Domingo, J., Huang, N., and Khush, G. S. 2001. Are the dominant and recessive plant disease resistance genes similar? A case study of rice $\mathrm{R}$ genes and Xanthomonas oryzae pv. oryzae races. Genetics 159:757-765.

Liu, B., Zhang, S., Zhu, X., Yang, Q., Wu, S., Mei, M., Mauleon, R., Leach, J., Mew, T., and Leung, H. 2004. Candidate defense genes as predictors of quantitative blast resistance in rice. Mol. Plant-Microbe Interact. 17: 1146-1152.

Liuv, B., Zhu, X. Y., Zhang, S., Wu, J., Han, S. S., Cho, Y. C., Roh, J., Leach, J., Liu, Y., Madamba, S., Bordeos, A., Baraoidan, M., Ona, I., Cruz, C. M., and Leung, H. 2009. What it takes to achieve durable resistance to rice blast? Pages 385-402 in: Advances in Genetics, Genomics and Control of Rice Blast Disease. X. Wang and B. Valent, eds. Springer, Netherlands.

Mahaffee, W. F., Thomas, C. S., Turechek, W. W., Ocamb, C. M., Nelson, M. E. Fox, A., and Gubler, W. D. 2003a. Responding to an introduced pathogen Podosphaera macularis (hop powdery mildew) in the Pacific Northwest Online. Plant Health Prog. (online) doi:10.1094/PHP-2003-1113-07-RV

Mahaffee, W. F., Turechek, W. W., and Ocamb, C. M. 2003b. Effect of variable temperature on infection severity of Podosphaera macularis on hops. Phytopathology 93:1587-1592.

McDonald, B. A., and Linde, C. 2002. Pathogen population genetics, evolutionary potential, and durable resistance. Annu. Rev. Phytopathol. 40:349-379.

Mundt, C. C. 1990 . Probability of mutation to multiple virulence and durability of resistance gene pyramids. Phytopathology 80:221-223.

Mundt, C. C. 1994. Techniques to manage pathogen co-evolution with host plants to prolong resistance. Pages 193-205 in: Rice Pest Science and Management. P. S. Teng, K. L. Heong, and K. Moody, eds. International Rice Research Institute, Los Baños, Philippines.

Mundt, C. C. 2014. Durable resistance: a key to sustainable management of pathogens and pests. Infect. Genet. Evol. 27:446-455.

Neve, R. 1991. Hops. Chapman and Hall, London. doi:10.1007/978-94-011-3106-3

Oberhollenzer, K., and Seigner, E. 2011. Resistance mechanisms of different hop genotypes to hop powdery mildew. Pages 21-24 in: Proc. Scientific Commission of the International Hop Growers Convention. E. Seigner, ed. June 21-25, Lublin, Poland.

Ocamb, C. M., Klein, R., Barbour, J., Griesbach, J., and Mahaffee, W. 1999 First report of hop powdery mildew in the Pacific Northwest. Plant Dis. $83: 1072$.

Palloix, A., Ayme, V., and Moury, B. 2009. Durability of plant major resistance genes to pathogens depends on the genetic background, experimental evidence and consequences for breeding strategies. New Phytol. 183:190-199.

Pariaud, B., Robert, C., Goyeau, H., and Lannou, C. 2009. Aggressiveness components and adaptation to a host cultivar in wheat leaf rust. Phytopathology 99:869-878.

Peetz, A. B., Mahaffee, W. F., and Gent, D. H. 2009. Effect of temperature on sporulation and infectivity of Podosphaera macularis on Humulus lupulus. Plant Dis. 93:281-286.

Poland, J. A., Balint-Kurti, P. J., Wisser, R. J., Pratt, R. C., and Nelson, R. J. 2009 Shades of gray: the world of quantitative disease resistance. Trends Plant Sci. 14:21-29.

Probst, C., Nelson, M. E., Grove, G. G., Twomey, M. C., and Gent, D. H. 2016 Hop powdery mildew control through alteration of spring pruning practices. Plant Dis. 100:1599-1605.

Quenouille, J., Montarry, J., Palloix, A., and Moury, B. 2013. Farther, slower, stronger: how the plant genetic background protects a major resistance gene from breakdown. Mol. Plant Pathol. 14:109-118.

Quenouille, J., Paulhiac, E., Moury, B., and Palloix, A. 2014. Quantitative trait loci from the host genetic background modulate the durability of a resistance gene: a rational basis for sustainable resistance breeding in plants. Heredity 112: 579-587.

Rouse, D. I., Nelson, R. R., MacKenzie, D. R., and Armitage, C. R. 1980 Components of rate-reducing resistance in seedlings of four wheat cultivars and parasitic fitness in six isolates of Erysiphe graminis f. sp. tritici. Phytopathology 70:1097-1100.

Rouxel, T., Penaud, A., Pinochet, X., Brun, H., Gout, L., Delourme, R., Schmit, J., and Balesdent, M. H. 2003. A 10-year survey of populations of Leptosphaeria 
maculans in France indicates a rapid adaptation towards the Rlm1 resistance gene of oilseed rape. Eur. J. Plant Pathol. 109:871-881.

Royle, D. 1978. Powdery mildew of the hop. Pages 381-409 in: The Powdery Mildews. D. M. Spencer, ed. Academic Press, London.

Seigner, E., Lutz, A., and Felsenstein, F. G. 2006. Wild hops: new genetic resources for resistance to hop powdery mildew (Podosphaera macularis spp. humuli). BrewingScience 59:122-129.

Seigner, E., Seefelder, S., Haugg, B., Hesse, H., Rosch, H., and Felsenstein, F. 2001. Investigations on the virulence spectrum of hop powdery mildew (Sphaerotheca humuli) and on the effectiveness of race-specific resistance genes. Pages 40-43 in: Proc. Scientific Commission International Hop Growers' Convention. E. Seigner, ed. Canterbury, England.

Sherman, J., and Gent, D. H. 2014. Concepts of sustainability, motivations for pest management approaches, and implications for communicating change. Plant Dis. 98:1024-1035.

St. Clair, D. A. 2010. Quantitative disease resistance and quantitative resistance loci in breeding. Annu. Rev. Phytopathol. 48:247-268.

Tan, M. A., Hutten, R. C., Visser, R. G., and van Eck, H. J. 2010. The effect of pyramiding Phytophthora infestans resistance genes R Pi-mcd1 and R Pi-ber in potato. Theor. Appl. Genet. 121:117-125.

Thomas, G. G. 1967. Hop studies by the late I. H. Williams. Rep. Dep. Hop Res. Wye Coll. 1966:63-67.
Turechek, W. W., and Mahaffee, W. F. 2004. Spatial pattern analysis of hop powdery mildew in the Pacific Northwest: implications for sampling. Phytophathology 94:1116-1128.

Turechek, W. W., Mahaffee, W. F., and Ocamb, C. M. 2001. Development of management strategies for hop powdery mildew in the Pacific Northwest. Plant Health Prog. (online). doi:10.1094/PHP-2001-0313-01-RS

Villaréal, L. M., and Lannou, C. 2000. Selection for increased spore efficacy by host genetic background in a wheat powdery mildew population. Phytopathology 90:1300-1306.

Wolfe, M. S., and Schwarzbach, E. 1978. Patterns of race changes in powdery mildews. Annu. Rev. Phytopathol. 16:159-180.

Wolfenbarger, S. N., Massie, S. T., Ocamb, C., Eck, E. B., Grove, G. G., Nelson, M. E., Probst, C., Twomey, M. C., and Gent, D. H. 2016a. Distribution and characterization of Podosphaera macularis virulent on hop cultivars possessing R6-based resistance to powdery mildew. Plant Dis. 100:1212-1221.

Wolfenbarger, S. N., Quesada-Ocampo, L. M., and Gent, D. H. 2016b. Powdery mildew caused by Podosphaera macularis on hop (Humulus lupulus) in North Carolina. Plant Dis. 100:1245.

Wolfenbarger, S. N., Twomey, M. C., Gadoury, D. M., Knaus, B. J., Grünwald, N. J., and Gent, D. H. 2015. Identification and distribution of mating-type idiomorphs in populations of Podosphaera macularis and development of chasmothecia of the fungus. Plant Pathol. 64:1094-1102. 